\title{
RESIST MATERIAL REQUIREMENTS FOR 256M AND 1G BIT DRAM FABRICATION
}

\author{
Naoaki Aizaki \\ ULSI Device Development Labs., NEC Corporation \\ 1120 Shimokuzawa, Sagamihara, Kanagawa 229, JAPAN
}

\begin{abstract}
Present status and recent advancement of resists in optical, EB and $X$-ray lithographies are reviewed from the viewpoint of next-generation LSI process engineering. The important issues for advanced resist technology development in these lithographies are discussed. For resists in optical lithographies ( $\mathrm{KrF}$ and ArF ), material optimization is the most critical issue to realize high transparency, high sensitivity and high dry-etching durability. For EB and X-ray resists, sensitivity is the most serious to get higher throughput. In order to be introduced in the mass production line, reproducibility must be improved correspondently to LSI design rule in each generation. Resist improvement and device application scenario are discussed for 256M and 1G DRAM production.
\end{abstract}

\section{INTRODUCTION}

The pattern size in high density memory devices has been steadily shrunk into sub-quarter micron range. In $256 \mathrm{M}$ and 1 GbitDRAM fabrication, the pattern size is designed to be 0.25 and $0.18 \mu \mathrm{m}$ respectively. To make such narrow patterns, many advanced lithography technologies are needed. The essential required items for lithography to fabricate $256 \mathrm{M} / 1 \mathrm{G}$ DRAM are resolution, linewidth control, overlay accuracy, depth of focus, field size, and throughput.

Candidates for $256 \mathrm{M} / 1 \mathrm{G}$ lithography are $\mathrm{KrF}$ excimer laser, ArF excimer laser, electron beam (EB), and X-ray lithographies. From the viewpoint of process compatibility, optical lithographies are most desirable. EB lithography has been widely used for mask making and sometimes used for ASIC devices but not used in DRAM production line because of its low throughput. X-ray lithography has the lowest compatibility with the present lithography line, therefore it has the highest barrier to be introduced in the production line. The most possible candidate for $256 \mathrm{M}$ fabrication is $\mathrm{KrF}$ with some resolution enhancement techniques. For the hole patterns, EB lithography may be used additionally. For $1 \mathrm{G}$ fabrication, no candidate has

Received May 20, 1995 
gotten the superior position.

In this paper, we review the present status of optical, EB and X-ray lithographies for these device generations. The important issues for advanced resist technology development in these lithographies are also discussed from the viewpoint of device/process engineering.

\section{PRESENT STATUS}

Requirements for 256M and 1G DRAM lithography in representative items are listed in Tab.1. The present status of optical, EB and X-ray lithographies is summarized in Tab.2.

Table 1 Requirements for $256 \mathrm{M}$ or 1G DRAM lithography

$\begin{array}{lcc} & 256 \mathrm{M} & 1 \mathrm{G} \\ \text { resolution }(\mu \mathrm{m}) & 0.25 & 0.18 \\ \text { depth of focus }(\mu \mathrm{m}) & 1.3 & 1.2 \\ \text { field size }(\mathrm{mm} \times \mathrm{mm}) & 28 \times 28 & 30 \times 30 \\ \text { linewidth control }(3 \sigma)(\mu \mathrm{m}) & 0.03 & 0.02 \\ \text { overlay }(\mathrm{X}+3 \sigma)(\mu \mathrm{m}) & 0.06 & 0.05 \\ \text { throughput }(8 " / \mathrm{Hr}) & 40 & 30 \\ \text { defect/damage free } & & \\ \text { environmental safety/health hazards } & & \\ \text { low cost } & & \end{array}$

Table 2 Present status of advanced lithographies

\begin{tabular}{|c|c|c|c|c|}
\hline & $\mathrm{KrF}(\mathrm{KrF}+\mathrm{PSM})$ & $\operatorname{ArF}(\mathrm{ArF}+\mathrm{TSI})$ & EB & $\mathrm{X}$-ray \\
\hline resolution $(\mu \mathrm{m})$ & $0.20(0.13)$ & $0.17(0.12)$ & 0.14 & 0.10 \\
\hline $\begin{array}{l}\text { sensitivity } \\
\left(\mathrm{mJ} / \mathrm{cm}^{2} \text { or } \mu \mathrm{C} / \mathrm{cm}^{2}\right)\end{array}$ & $20-30$ & $60-200$ & $10-20$ & $70-200$ \\
\hline $\mathrm{DOF}(\mu \mathrm{m})(0.25 \mu \mathrm{mL} / \mathrm{S})$ & 1.0 & & & \\
\hline$(0.18 \mu \mathrm{mL} / \mathrm{S})$ & $(>1.0)$ & $(1.0)$ & & \\
\hline$(0.15 \mu \mathrm{mL} / \mathrm{S})$ & & $(0.75)$ & $>20$ & $>10$ \\
\hline $\operatorname{overlay}(\mathrm{X}+3 \sigma)(\mu \mathrm{m})$ & 0.07 & --- & 0.07 & 0.07 \\
\hline field size $(\mathrm{mm} \times \mathrm{mm})$ & $22 \times 22$ & $3 \times 3$ & no limit & $25 \times 25$ \\
\hline stability (equipment) & good & poor & good & fair \\
\hline (process) & fair & --- & fair & fair \\
\hline throughput (6"/Hr) & 50 & -- & 12 & 15 \\
\hline
\end{tabular}


Between the items in Tab. 2, resolution, sensitivity, depth of focus (DOF), throughput and cost are resist related. The material design basically determines resolution and sensitivity, and the process parameters optimization limits the actual characteristics. DOF and throughput are limited by the exposure system itself and the resist characteristics. Moreover, the patterned resist profile must be sufficiently steep, which is determined by the optimization of the resist materials and the process parameters. Focusing on resolution and sensitivity, problems and recent developments in each lithography are reviewed in following sections.

\section{PROBLEMS}

Problems listed in Tab.3 are urgent in each lithography to improve the resist performance. In $\mathrm{KrF}$ wavelength range, the novolac resin, which has excellent characteristics (especially dissolution discrimination, bleaching and dry-etching durability) as g-line or i-line resist, has a strong absorption. Moreover, higher sensitivity comparing with $\mathrm{i}$-line resist is needed. These problems are seemed to be solved only by using chemically amplified resist (CAR) scheme [1].

Table 3 Urgent issues to improve the resist performance

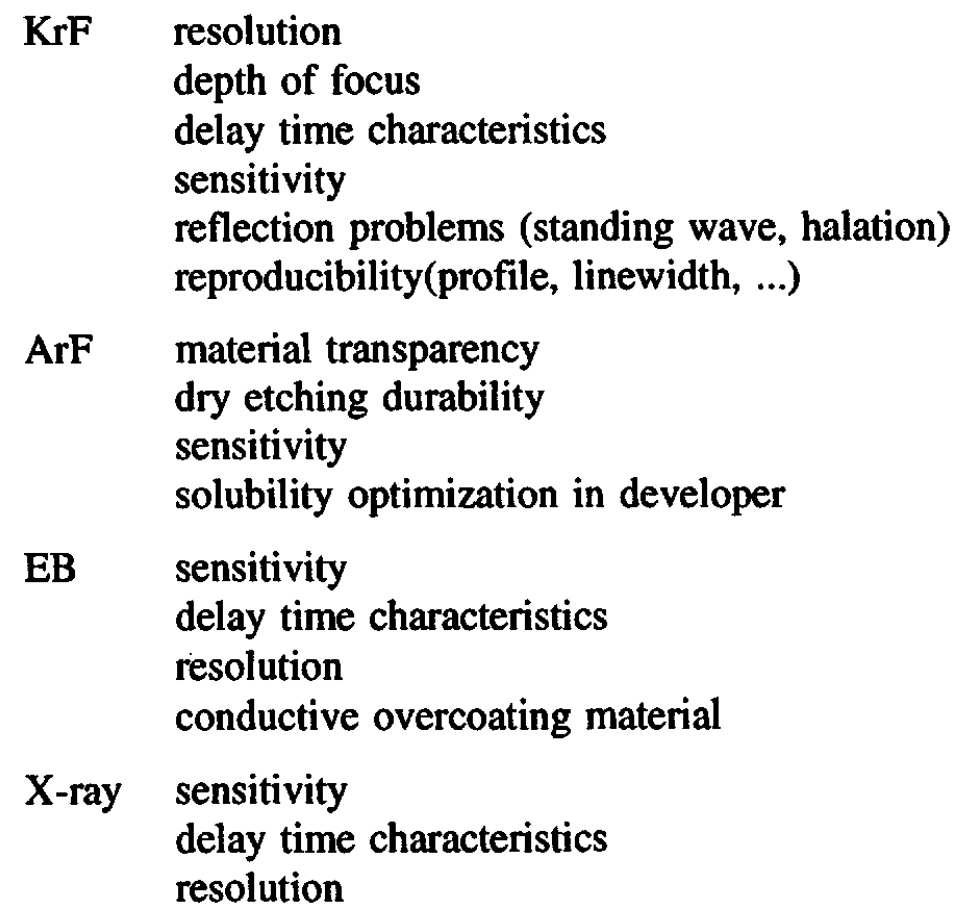


The tert-butoxycarbonyl (t-BOC) protected poly-hydroxystyrene (PHS) is the representative candidate as a base resin for $\mathrm{KrF}$ resist. Combined with many kinds of acid generator and additional dissolution inhibitor, many works have been done to improve resist performance. The results are sufficient for the prototype fabrication level but not for the mass production level of $0.25 \mu \mathrm{m}$ pattern devices. The inherent resist characteristics and the process stability, such as resolution, sensitivity, focus latitude, exposure dose latitude, standing wave effect and delay time effect, must be improved in order to be used in $0.25 \mu \mathrm{m}$ device production. Combination of $\mathrm{KrF}$ lithography with some kind of resolution enhancement technique (RET) is useful to improve the resolution limit and DOF but there are some limitations in each RET, such as pattern layout, necessity of nega-type resist and mask structure complexity.

In ArF resist field, the reports are not so many and the resultant level is not matured. Many more works are needed to develop all items in ArF lithography, however obtained beginning results show the possibility of high resolution by this lithography. In ArF wavelength range, the absorption problem is more severe than that in $\mathrm{KrF}$ range. The styrene-based polymer, which can be used as the base material in $\mathrm{KrF}$ resist, has a strong absorption in ArF wavelength range.

There are two choices to overcome this problem. First is to find another high transparency materials. Second is to adopt other resist scheme; for example, a top-surface imaging (TSI) scheme or a multi-layer scheme. For single-layer resist scheme, the important issues are the sufficiently transparent resist materials (base resin, acid generator and dissolution inhibitor) and the dry-etching durability. For TSI scheme, the important issues are the high contrast and the process simplicity.

In EB lithography, the inherent resolution meets the demand for 1G DRAM. The optical transparency is not necessary, so there can be wider choices as EB resist materials than as $\mathrm{KrF}$ or ArF resist materials. The most serious problem is throughput. From the viewpoint of resist, the sensitivity improvement is most effective to improve throughput. For that purpose, CAR is also effective in EB resist. Until now, many materials (resin, acid generator and dissolution inhibitor/crosslinker) are investigated to improve resist characteristics. The recent resists have been improved in resolution, sensitivity and delay time effect but more improvement is needed.

The resultant resolution is also determined by beam blur and by scattering effect. These are mainly belonging to the machine issue but the optimization of resist/process parameters is 
also effective to improve the resultant resolution.

In X-ray lithography, the resolution limit and the profile steepness of resultant patterns are inherently excellent. The improvement of resist sensitivity is desired to increase the throughput. The most severe problem is the compatibility of X-ray lithography system concept itself with the present optical system in mass production.

In all lithographies, the reproducibility is the important item at the last stage of resist improvement. Especially, the linewidth control ( CD control ) becomes more severe. Because the linewidth tolerance becomes more critical as the circuit design rule becomes smaller and the electric resistance variation becomes more critical.

\section{RECENT DEVELOPMENTS}

Recently, these problems listed in Tab.3 have been eagerly investigated and improved in each lithography as follows.

\subsection{KrF Resist}

Many attempts to improve the CAR characteristics have been reported recently. As the base resin, other than $\mathrm{t}-\mathrm{BOC}$ protected PHS, some variations are reported, such as tetrahydropyranyl (THP) protected PHS [3], poly(t-butoxycarbonyloxystyrene-sulfone) (PTBSS) [4], poly(4-acetoxystyrene-4-t-butoxycarbonyloxystyrene-sulfone) (PASTBSS) [5], silylated polyhydroxystyrene (SiPHS) [6], Poly(3-methyl-4-hydroxystyrene)/ply(4-hydroxystyrene) (PMHS/PHS) [7], and so on. There are, of course, many kinds of photoacid generators and dissolution inhibitors/crosslinkers, which are not mentioned here.

The improvement in resolution and sensitivity have been obtained by component materials and their ratio optimization in a resist composed of t-BOC-protected PHS, benzenesulfonic acid derivative as a photoacid generator (PAG) and an additional dissolution inhibitor [8,9]. Based on the dissolution characteristics analysis, a steep slope of the dissolution rate curve, moderate dissolution contrast and adequate acid diffusion length are important factors to realize ideal dissolution characteristics leading to $0.25 \mu \mathrm{m}$ pattern formation capability. After optimization of protection ratio, molecular weight and PEB temperature, the resolution limit of $0.22 \mu \mathrm{mL} / \mathrm{S}$, the sensitivity of $30 \mathrm{~mJ} / \mathrm{cm}^{2}$ and the focus margin of $1.0 \mu \mathrm{m}$ at $0.25 \mu \mathrm{mL} / \mathrm{S}$ have been obtained [8]. For wider practical process latitude, the exposure latitude is important as well as the focus latitude. These latitude evaluations must be done before the introduction into the mass 
production.

From the viewpoint of process latitude, the delay time effect is the serious and inherent problem to be improved and resolved. The origin and the mechanism have been almost cleared $[7,10,11]$. Recent improvement to suppress the delay time effect are classified into these categories; atmosphere filtering, overcoat, resist material optimization (low $\mathrm{Tg}$ base resin [2] and additional material in base resin (sulfonic compound)), and pre-annealing at higher temperature than $\mathrm{Tg}$ [2]. Using these techniques, the allowed interval time between exposure and postexposure baking has been extended. The stability of that characteristics is the remained problem.

The interaction with underlayer materials [12] and the T-top profile [3] have a similar effect to deteriorate the pattern profile as the delay time effect. The understanding of these problems have been developed but not fully at present. These problems are understood as the decrease of acid generator and can be improved by the process parameters optimization in underlayer fabrication or the overcoating layer application.

The photobleaching is very effective to get the steep profile and to avoid the problems originated from the substrate reflection such as the standing wave effect and the halation effect. However, it may be the most difficult feature to be realized in CAR. Because CAR utilizes the acid catalysis which is actualized after exposure as PEB not in the period of exposure when the photobleaching is needed. Another additional material must be introduced to realize that kind of feature.

When the photobleaching is impossible, other techniques are needed. The resist with a light-absorbing dye and the anti-reflection coating have been investigated. The dye-containing resist must satisfy contradictory two demands; high transparency to get a steep resist profile and moderate absorption to avoid the standing wave effect. There are no satisfactory results in dyecontaining resist scheme at present.

There are two types of the anti-reflection layer; top-surface anti-reflection type (TAR) and bottom layer type (ARC). TAR is effective to avoid the standing wave effect but not effective to suppress the halation. ARC is effective to both phenomena. For both methods, optimized materials have been investigated. From the viewpoint of practicality, TAR is easier to be processed.

In the process of optimization in materials and process conditions, the simulation technique is very important and useful. Fast 3D simulation program is desired to estimate the 
exposed and developed resist patterns in actual device structure. Between many parameters which are necessary in these simulation, the acid diffusion length value is most difficult to be measured accurately.

Before the combination with RET is utilized, the process latitude and the process controllability must be thoroughly evaluated. In the case of the modified illumination, the evaluation of line width controllability and the focus latitude variation between dense and sparse patterns are especially important. In the case of the Levenson-type phase shift mask, CAD for an automatic shifter pattern layout must be prepared for circuit engineers.

\subsection{ArF Resist}

As mentioned above, there are two choices to overcome the strong absorption problem; other high transparency materials or other resist schemes.

For the mass production application, a single-layer scheme is desirable. Methacrylate, alicyclic and naphthalene polymers have been reported recently as the high transparency ArF single-layer resist material; Poly(methylmethacrylate-co-t-butylmethacrylate-co-methacrylic acid) P(MMA-tBuMA-MAA) [13], Poly(isobornylmethacrylate-co-methylmethacrylate-co-tbutylmethacrylate-co-methacrylic acid) P(IBMA-MMA-tBuMA-MAA) [17], Poly(tricyclodecanylacrylate-co-tetrahydropyranylmethacrylate-co-methacrylic acid) P(TCDATHPMA-MAA) [14], Poly(adamantylmethacrylate-co-3-oxocyclohexylmethacrylate) P(AdMAOCHMA) [15] and Poly(tert-butylmethacrylate-co-methylmethacrylate-co-methacrylic acid-co-2nahthylmethacrylate) P(tBuMA-MMA-MAA-2NpMA) [16]. They have a transparency needed as ArF resist. From the viewpoint of dry-etching durability, alicyclic or naphthalene polymer is better. At present, these resists are not sufficient, because that resolution is inferior than expected and theoretical one and the process compatibility and the stability are poor. The development conditions and the delay time problems must be improved.

TSI scheme has resulted the most superior resolution in ArF lithography. In this scheme, the absorption of exposure light is not harmful but benefitable. Key issue is not a base material but a silylating agent. Many works have been reported on the silylation results in i-line [18] and $\mathrm{KrF}$ [19] lithography with gas [20] and liquid [21] phase silylation agent but not so many in ArF lithography.

Recently, ArF works by silylation have been reported using novolac polymer or PHS with dimethylsilyldimethylamine (DMSDMA) in vapor phase [22], or using PHS with 
bis(dimethylamino)methylsilane (B(DMA)MS) in liquid phase [23]. To get dense silylated layer, the latter liquid phase silylating agent with multifunctional group is more effective. Remained major problems in materials optimization are suppression of swelling in silylated area, harmless resist removal after patterning, and suitable silylation method for mass production. As the other multi-layer resist scheme, bilayer resists using polysilanes and polysilynes are reported [24].

TSI and multi-layer resist schemes have a drawback to need more process steps compared with the single-layer resist scheme. Recent reports on advanced $\mathrm{KrF}$ resist systems are usually using additive layers, anti-reflection layer ( bottom, top, or both ) and overcoating anti-delaytime-effect layer. From this tendency, this drawback may not so much complicated. Especially, TSI is simpler than that complicated single-layer scheme, except that the dry-development is somewhat complicated and troublesome at present comparing with the conventional wet development. The conclusion will be decided by the total comparison between them when $\operatorname{ArF}$ lithography is totally improved and come near to the suitable level for mass production.

\subsection{EB Resist}

In the case of EB resist, the optical transparency is not necessary. This is an advantage comparing to the other $\mathrm{KrF}$ and ArF resists. As the base resin, the cresol nobolac, which has a high dry-etching durability, can be used.

From the viewpoint of high throughput, the resist sensitivity must be high. The target level is $<10 \mu \mathrm{C} / \mathrm{cm}^{2}$. Recently, some resists have been reported to have high sensitivity around this target level as well as high resolution equal to or smaller than $0.20 \mu \mathrm{m}$. These resists are summarized in Tab. 4 and 5. The main problem in these resists is PED characteristics. The resolution is required to be improved. The posi-type resist shows a distinct top corner profile. However, the nega-type resist has the tendency to result a round top profile.

In Tabs. 4 and 5, in general, a higher resolution resist has a lower sensitivity. Of course, comparing to the preceding resists, they are superior in both criteria. There may be some other possibilities to improve resist characteristics in both criteria simultaneously by some optimization of material design and process parameters.

Usually, some overcoating layer is necessary to avoid the charging during the pattern exposure. The conductive resist material is desirable but the coexistence of an excellent pattern formation and an superior conductance seems to be very difficult. 
Table 4 Newly developed nega-type EB resists

\begin{tabular}{|c|c|c|c|c|c|}
\hline & $\begin{array}{l}\text { resolution } \\
(\mu \mathrm{m} \mathrm{L} / S)\end{array}$ & $\begin{array}{r}\text { sensitivity } \\
\left(\mu \mathrm{C} / \mathrm{cm}^{2}\right)\end{array}$ & $\begin{array}{l}\text { base } \\
\text { resin }\end{array}$ & crosslinker & $\begin{array}{l}\text { acid } \\
\text { generator }\end{array}$ \\
\hline Resist EBN1 & 0.16 & 18.0 & nobolac & melamine & $\begin{array}{l}\text { bromine } \\
\text { compound }\end{array}$ \\
\hline Resist EBN2 & 0.20 & 7.5 & PHS & melamine & $\begin{array}{l}\text { bromine } \\
\text { compound }\end{array}$ \\
\hline Resist EBN3 & 0.20 & 10.0 & PHS & melamine & $\begin{array}{l}\text { sulfonic } \\
\text { acid }\end{array}$ \\
\hline Resist EBN4 & 0.20 & 14.0 & nobolac & melamine & $\begin{array}{l}\text { bromine } \\
\text { compound }\end{array}$ \\
\hline
\end{tabular}

Table 5 Newly developed posi-type EB resists

\begin{tabular}{|c|c|c|c|c|c|}
\hline & $\begin{array}{l}\text { resolution } \\
(\mu \mathrm{m} \text { Hole })\end{array}$ & $\begin{array}{r}\text { sensitivity } \\
\left(\mu \mathrm{C} / \mathrm{cm}^{2}\right)\end{array}$ & $\begin{array}{l}\text { base } \\
\text { resin }\end{array}$ & $\begin{array}{l}\text { dissolution } \\
\text { inhibitor }\end{array}$ & $\begin{array}{l}\text { acid } \\
\text { generator }\end{array}$ \\
\hline Resist EBP1 & 0.14 & 14.0 & PHS & ---- & $\begin{array}{l}\text { sulfonic } \\
\text { acid }\end{array}$ \\
\hline Resist EBP2 & 0.18 & 8.5 & nobolac & ----- & $\begin{array}{l}\text { onium } \\
\text { salt }\end{array}$ \\
\hline Resist EBP3 & 0.18 & 8.5 & nobolac & $\begin{array}{l}\text { sulfonic } \\
\text { acid }\end{array}$ & THP \\
\hline
\end{tabular}

\subsection{X-ray Resist}

In X-ray resist, the optical transparency is not necessary as in EB resist and the resultant resist profile is excellently steep generally, because that usual organic resist materials are highly transparent to X-ray and the scattering effect as in EB resist is negligible. This is an advantage comparing to the other resists. As the base resin, the cresol nobolac, which has a high dryetching durability, can be used.

From the viewpoint of high throughput, the resist sensitivity must be high. The target level is $<100 \mathrm{~mJ} / \mathrm{cm}^{2}$. Recently, some resists have been reported to have high sensitivity on this target level and high resolution equal to or smaller than $0.20 \mu \mathrm{m} \mathrm{[25].}$

The important remained problem in these resists is delay time characteristics. The resolution is also required to be some more improved, but this is primarily related with the advancement of the mask technology. 
Table 6 Resist improvement and application scenario

$\mathrm{KrF} \quad$ (1) used in $256 \mathrm{M}$ production

...in improved sensitivity

...in improved reproducibility (stability)

...with overcoat to avoid delay time effect

...with TAR/ARC to avoid the reflection problems

...in mix/match scheme with i-line exposure tool

...with some kinds of RET

(2) maybe used in early stage of $1 \mathrm{G}$ production

...in improved resolution

...with high efficiency RET

ArF (1) used in/after middle stage of $1 \mathrm{G}$ production

...in single layer scheme

...with overcoat to avoid the delay time effect

...with TAR/ARC

(2) probably used in $4 \mathrm{G}$ production

...in single layer scheme with some kinds of RET

...in TSI or multi-layer scheme (without overcoat and ARC)

EB (1) used in $1 G$ and $4 G$ prototype fabrication

...in single layer scheme

...in improved resolution

...with overcoat to avoid the charging

...with innovative high-throughput system

(2) probably used in $1 \mathrm{G}$ and $4 \mathrm{G}$ production

...in revolutionary high-sensitive resist scheme

...with revolutionary high-throughput system

$\mathrm{X}$-ray (1)has the probability to be used in $1 \mathrm{G}$ and $4 \mathrm{G}$ production

....after feasibility check for production line

...with innovative high-stability mask and system

\section{IMPROVEMENT AND APPLICATION SCENARIO}

Table 6 shows the prospects for resist improvement scenario in near future in each lithography, which shows, on the other hand, the requirements from the viewpoint of the device mass production. As above mentioned, $\mathrm{KrF}$ resist has more issues to be improved than any other kind of resist. This means that KrF resist has many severe problems because of its shorter wavelength, and also means that it is a most advanced candidate toward the introduction into the next-generation mass production line. Any other kind of resist must be confronted with process- 
related optimization problems on the way to the higher developed stage.

In these scenarios, the resist process simulation is very important and the parameter measurement is also important. Especially, the parameters about the acid diffusion such as diffusion length are crucial to estimate the resultant pattern profile and to improve the resist materials. And solvents in each lithography must be selected to ensure environmental safety. Resist cost will be lowered according to the market expansion. However,on the other hand, the possibility for cost lowering is important to stimulate the market expansion.

We eagerly hope each kind of resist make a rapid progress to be in time for these generation of LSIs. For that purpose, the research fund of money and information must be managed more effectively, because that the difficulty and barrier before this progress seemed to be incomparably complicated and to need well-related extensive works to decide which lithography is effective and necessary for the near future LSI production.

\section{Acknowledgments}

The author would like to thank T.Itani, T.Ohfuji, H.Yoshino, K.Nakano, K.Maeda, K.Nakajima, K.Kasama, H.Nozue and K.Suzuki for many useful and helpful discussions. He would also like to thank Drs. M.Kamoshida, K.Okada, M.Kikuchi and N.Endo for their encouragement and support.

\section{References}

[1]. H.Ito, C.G.Willson, and J.M.J.Frechet, Digest of Technical Papers of 1982 Symposium on VLSI Technology, p.86(1982).

[2]. H.Ito, W.P.England, R.Sooriyakumaran, N.J.Clecak, G.Breyta, W.D.Hinsberg, H.Lee, and D.Y.Yoon, J. Photopolym. Sci, Technol. 6(1993)547.

[3]. S.A.M.Hesp, N.Hayashi, and T.Ueno, J. Appl. Polym. Sci., 42(1991)877.

[4]. O.Nalamasu, M.Cheng, A.G.Timko, V.Pol, E.Reichmanis, and L.F.Thompson, J. Photopolym. Sci. Technol. 4(1991)299.

[5]. O.Nalamasu, A.E.Novembre, J.M.Kometani, and J.E.Hanson, J. Photopolym. Sci. Technol. 6(1993)457.

[6]. M.Murata, E.Kobayashi, M.Yamachika, Y.Kobayashi, Y.Yumoto, and T.Miura, J. Photopolym. Sci. Technol. 5(1992)79. 
[7]. H.Roschert, K.-J.Przybilla, W.Spiess, H.Wengenroth, and G.Pawlowski, Proc. SPIE 1672(1992)33.

[8]. T.Itani, H.Iwasaki, M.Fujimoto, and K.Kasama, Jpn. J. Appl. Phys. 33(1994)7005.

[9]. T.Itani, H.Iwasaki, H.Yoshino, M.Fujimoto, and K.Kasama, Proc. SPIE 2438-07(1995).

[10]. S.A.MacDonald, N.J.Clecak, H.R.Wendt, C.G.Willson, C.D.Snyder, C.J.Knors, N.B.Deyoe, J.G.Maltabes, J.Morrow, A.E.McGuire, S.J.Holmes, Proc. SPIE 1466(1991)2.

[11]. O.Nalamasu, E.Reichmanis, M.Cheng, V.Pol, J.M.Kometani, F.M.Houlihan, T.X.Neeman, M.P.Bohrer, D.A.Mixon, and L.F.Thompson, Proc. SPIE 1466(1991)13.

[12]. T.Naito, O.Sasaki, T.Tada, N.Kihara, T.Ushiroguchi, and S.Saito, J. Photopolym. Sci. Technol. 6(1993)315.

[13]. R.R.Kunz, R.D.Allen, W.D.Hinsberg, and G.M.Wallraff, Proc. SPIE 1925(1993)167.

[14]. K.Nakano, K.Maeda, S.Iwasa, T.Ohfuji, and E.Hasegawa, Proc. SPIE 2438-20(1995).

[15]. M.Takahashi, S.Takechi, K.Nozaki, Y.Kaimoto, I.Hanyu, and N.Abe, Proc. SPIE 234819(1995).

[16]. T.Naito, K.Asakawa, N.Shida, T.Ushiroguchi, and M.Nakase, Jpn. J. Appl. Phys. 33(1994)7028.

[17]. R.D.Allen, G.M.Wallraff, R.A.DiPietro, D.C.Hofer, and R.R.Kunz, Proc. SPIE 243867(1995).

[18]. F.Coopmans and B.Roland, Solid State Technol., June(1987)93.

[19]. M.Op de Beeck and L.Van den Hove, J. Vac. Sci. Technol., B10(1992)701.

[20]. K.-H.Baik, L.Van den Hove, A.M.Goethals, M.Op de Beeck, and B.Roland, J. Vac. Sci. Technol., B8(1990) 1481.

[21]. J.M.Show, M.Hatzakis, E.D.Babich, J.R.Paraszczak, D.F.Witman, and K.J.Stewart, J. Vac. Sci. Technol., B7(1989)1709.

[22]. M.A.Hartney, D.W.Johnson, A.C.Spencer, Proc. SPIE 1466(1991)238.

[23]. K.Maeda, T.Ohfuji, N.Aizaki, and E.Hasegawa, Proc. SPIE 2438-23(1995).

[24]. M.W.Horn, B.E.Maxwell, R.R.Kunz, M.S.Hibbs, S.C.Palmateer, and A.R.Forte, Proc. SPIE 2438-35(1995).

[25]. H.Ban, J.Nakamura, K.Deguchi, and A.Tanaka, J. Vac. Sci. Technol., B12(1994). 